\title{
Bulk oxygen in a-silicon nitride and its effect on IR absorption
}

P. S. LAKSHMINARASIMHAM, P. S. GOPALAKRISHNAN

Materials Science Division, National Aerospace Laboratories Bangalore - 560017 India

There have been several studies of the oxygen content in a-silicon nitride. It was, in fact, thought to be an oxynitride and compositions such as Sitl.5N15005 and Si76N100O2 were proposed for it $[1,2]$. However, later studies $[3,4]$ have shown that oxygen is not required to stabilize the structure of asilicon nitride. Studies $[5,6]$ of the sintering of silicon nitride have shown the importance of the surface oxide layer which is known to be present in all silicon nitride powders. During sintering, this surface oxide reacts with sintering additives forming liquid phases in which the a-silicon nitride dissolves and reprecipitates as a-silicon nitride. Thus the nature and amount of sintering aids needed depends upon the extent of oxygen present on the surface. In this connection there has been a detailed study [7] of the oxygen distribution both in the bulk and on the surface in several silicon nitride samples. It was observed that silicon nitride prepared by the decomposition of silicon imide had the lowest oxygen content and most of this oxygen was on the surface. On the other hand, silicon nitride prepared by the carb thermal reduction of silica had the largest $(-3 \%$ by wht) percentage of oxygen and a large portion of it was in the bulk. This was thought to be due to the incomplete nitridation of silica. There have also been several studies $[8,9]$ on the determination of the crystal structure of a-silicon nitride. Because of the very similar atomic scattering factors for nitrogen and oxygen, X-ray diffraction studies have not been able to directly prove the presence of oxygen in a-silicon nitride. Its presence has only been indirectly estimated by adjusting a partial occupancy for oxygen in place of nitrogen during structure refinement. Thus the existence of bulk oxygen in the lattice of a-silicon nitride is still not conclusively proven.

In our laboratory, silicon nitride, primarily aphase, was prepared by different methods and either powder or whiskers obtained, depending upon the method of preparation. On characterizing the samples it was observed that they had almost identical XRD patterns, whereas their IR absorption spectra showed significant differences. This prompted an investigation and the results of this investigation are reported here.

Four different samples of silicon nitride were prepared by different procedures: (a) ammonolysis of silicon powder [10]; (b) nitridation of an equimolar mixture of silicon and silica; (c) carbothermal reduction of_silica; and (d) nitridation of silicon whiskers [11]. Methods (a) and (b) yielded whiskers whereas method (c) resulted in powder. Method (d) gave whisker-like pseudomorphs. The XRD patterns of these four samples are shown in Fig. 1. It can be seen that the samples contain mostly a-phase, the J3phase content is very small. It may be noted that the patterns are almost identical except for small changes in the relative intensities of the lines. The changes in the lattice parameters of the samples are also quite small. IR absorption spectra of the same samples are a

I

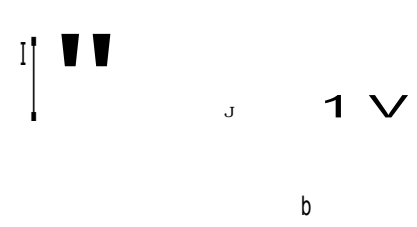

c

d
40

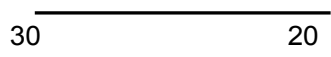

20 CuK,.. (degrees)

Figure 1 X-ray diffraction patterns of the four different samples of silicon nitride (for details see the text). Lines marked with a dot are due to /3-phase. 
shown in Fig. 2. It can be seen that the spectra of the samples prepared by methods (a) and (b), surprisingly, do not have the characteristic absorption around $950 \mathrm{~cm}$ which corresponds to $\mathrm{Si}-\mathrm{N}-\mathrm{Si}$

b

0

C

IT

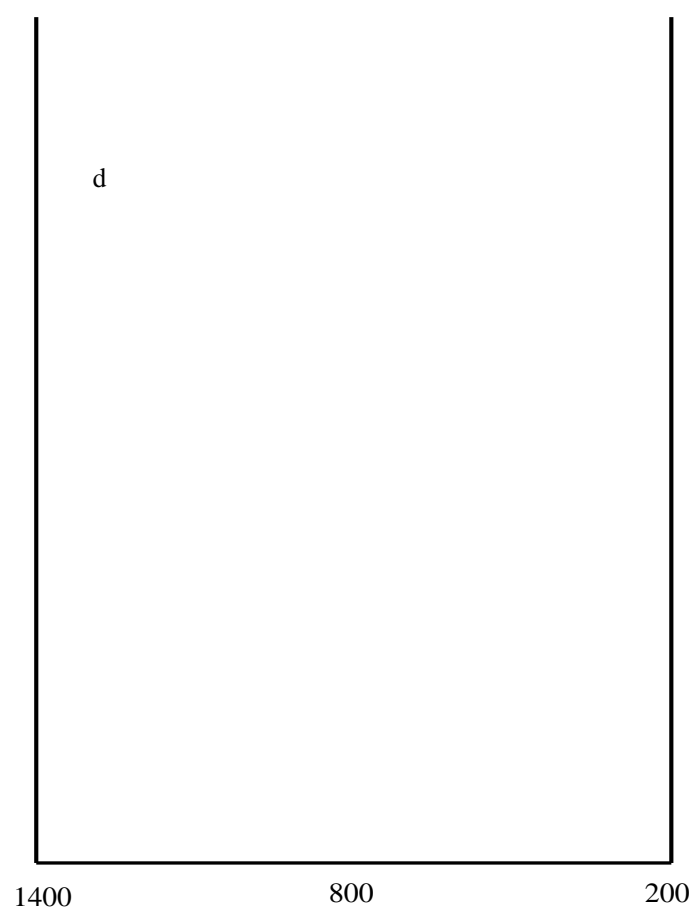

Wavenumber $\left(\mathrm{cm}^{1}\right)$

Figure 2 Infrared spectra of the four different samples of silicon nitride (note the difference in absorption around $950 \mathrm{~cm}^{-1}$ ). antisymmetric stretching mode [12]. Sample (d) has the highest absorption at this wave number. It may be noted that samples obtained in whisker form have the least absorption in this region. Also, the other absorption peaks in the region from $800-950 \mathrm{~cm}^{-1}$ are much more pronounced in samples (a) and (b). This observation raised some doubt concerning the extent of nitrogen content in the samples. Therefore, the nitrogen content in the samples was estimated by Kjeldahl's method: sample digestion was maintained for a period of $6 \mathrm{~h}$ and selenium was used as a catalyst to facilitate complete dissolution. The following values for the nitrogen content were obtained: (a) 36.3\%; (b) 37.2\%; (c) $38.7 \%$; and (d) $39.2 \%$. Thus samples (a) and (b), which show low IR absorption at $950 \mathrm{~cm}$ ' have considerably lower nitrogen content than the theoretical value of $39.93 \%$. Since all the samples were prepared from pure starting materials, it can be surmised that these samples may contain correspondingly more oxygen. If this oxygen is due to the presence of silica, the IR absorption spectra should have shown the characteristic peaks of silica. The XRD patterns also should have shown either the lines of crystalline silica or the diffuse halos of amorphous silica. Moreover, IR absorption spectra of a mixture of silicon nitride and silica cannot account for lower absorption specifically at $950 \mathrm{~cm}$ Therefore, the oxygen present must be in the bulk. To confirm this, a few grams of the silicon nitride samples (in the form of whiskers) were mixed with excess of carbon and heated at $1450{ }^{\circ} \mathrm{C}$ for $5 \mathrm{~h}$ while passing ammonia. The excess carbon was removed later by heating in air at $800{ }^{\circ} \mathrm{C}$. The IR absorption spectra of these samples showed the characteristic absorption at $950 \mathrm{~cm}^{-\mathbf{I}}$ similar to that of samples (d). This clearly shows that oxygen was present in the silicon nitride samples and it was, indeed, in the bulk.

The structures of silica and silicon nitride essentially consist of $\mathrm{SiO}_{4}$ and $\mathrm{SiN}_{4}$ tetrahedra which are linked through the corners. It appears that during the growth of a-silicon nitride from the $\mathrm{SiO}$ vapour, a small fraction of $\mathrm{SiO}$ is incorporated without nitridation in the lattice of a-silicon nitride. The consequent $t$ imbalance in the charge may be compensated by 'silicon vacancies. It may therefore be . concluded that although it is not necessary that asilicon nitride should have bulk oxygen to stabilize its structure, it can accommodate a considerable amount of bulk oxygen without becoming oxynitride structurally.

\section{Acknowledgements}

The authors thank Dr S. Usha Devi for the X-ray diffraction patterns and Dr Sudha Mahadevan for making the IR spectrophotometer available to us.

\section{References}

1. S. WILD, P. GRIEVESON and K. H. JACK, in "Special ceramics 5" edited by P. Popper (British Ceramic Research Association, Stoke-on-Trent, 1972) p. 385. 
2. I. COLQUHOUN, S. WILD, P. GRIEVESON and K. H. JACK, Proc. Brit. Ceram. Soc. 22 (1973) 207.

3. A. J. EDWARDS, D. P. ELIAS, M. W. LINDLEY, A. ATKINSON and A. J. MOULSON, J. Mater. Sci. 9 (1974) 516.

4. K. KIJIMA, K. KATO, Z. INOUE and H. TANAKA, ibid. 10 (1975) 362.

5. G. WOTTING and G. ZIEGLER in Proceedings of 1st International Symposium Ceramic Components for Engines, edited by S. Somiya (KTK Scientific Publications, Tokio, 1983) p. 412.

6. G. NIETFELD, U. WICKEL and G. WOTTING in Proceedings of 2nd International Conference Ceamic Powder Process Science, edited by H. Hanser, G. L. Messing and S. Hirano (Deutsche Keramische Gesellschaft, 1989) p. 795.

7. M. PEUCKERT and P. GREIL, J. Mater. Sci. 22 (1987) 3717.
8. K. KATO, Z. INOUE, K. KIJIMA, I. KAWADA, H. TANAKA and T. YAMANE, J. Amer. Ceram. Soc. 58 (1975) 90

9. P. R. MARCHAND, Y. LAURENT and J. LANG, Acta Crystallogr. B 25 (1969) 2157.

10. P. S. GOPALAKRISHNAN and P. S. LAKSHMINARASIMHAM, J. Mater. Sci. Lett. $\mathbf{1 2}$ (1993) 1422.

11. Idem., ibid. 14 (1995) 31.

12. J. P. LUONGO, J. Electrochem. Soc. 130 (1983) 1560.

Received 28 March

and accepted 6 June 1995 